\title{
Value addition of corn husks through enzymatic production of xylooligosaccharides
}

\author{
Ashis Kumar Samanta ${ }^{1 *}$; A.P. Kolte ${ }^{1}$, A.V. Elangovan ${ }^{1}$, A. Dhali ${ }^{1}$, S. Senani ${ }^{1}$, M. \\ Sridhar $^{1}$, K.P. Suresh ${ }^{2}$, N. Jayapal ${ }^{1}$, C. Jayaram ${ }^{1}$ and Sohini Roy ${ }^{1}$ \\ ${ }^{1}$ ICAR-NIANP, Adugodi, Karnataka, India; ${ }^{2}$ ICAR-NIVEDI, Ramagondanahalli, Yelahanka, Karnataka, India
}

\begin{abstract}
Corn husks are the major wastes of corn industries with meagre economic significance. The present study was planned for value addition of corn husk through extraction of xylan, followed by its enzymatic hydrolysis into xylooligosaccharides, a pentose based prebiotic. Compositional analysis of corn husks revealed neutral detergent fibre $68.87 \%$, acid detergent fibre $31.48 \%$, hemicelluloses $37.39 \%$, cellulose $29.07 \%$ and crude protein $2.68 \%$. Irrespective of the extraction conditions, sodium hydroxide was found to be more effective in maximizing the yield of xylan from corn husks than potassium hydroxide (84\% vs. 66\%). Application of xylanase over the xylan of corn husks resulted into production of xylooligosaccharides with different degree of polymerization namely, xylobiose and xylotriose in addition to xylose monomer. On the basis of response surface model analysis, the maximum yield of xylobiose $(1.9 \mathrm{mg} / \mathrm{ml})$ was achieved with the enzymatic hydrolysis conditions of $\mathrm{pH} 5.8$, temperature $44^{\circ} \mathrm{C}$, enzyme dose $5.7 \mathrm{U} / \mathrm{ml}$ and hydrolysis time of $17.5 \mathrm{~h}$. Therefore, the corn husks could be used as raw material for xylan extraction vis a vis its translation into prebiotic xylooligosaccharides.
\end{abstract}

Key words: Corn waste, xylan extraction, prebiotic, enzymatic process, XOS

\footnotetext{
${ }^{1}$ Authors for correspondence: drashiskumarsamanta@gmail.com
} 


\section{INTRODUCTION}

Currently the plant derived bioactive molecules are being explored for health, wellbeing, fortification or supplementation of food because of growing consumer awareness coupled with phobia against the chemical compounds. This has lead to the development of the novel concept of 'prebiotic' in the field of functional food science during the mid nineties of previous century (Gibson and Roberfroid 1995). The prebiotics are bioactive molecules that essentially works on the principle of "prevention is better than cure" in order to lengthening the quality of human-life by preventing the unwarranted lifestyle diseases as well as age related issues (Samanta et al. 2015). The issues associated with handling of probiotic organisms and their survivability at the site of action has been raised by researchers on several occasions (Reid 2008). The bioactive molecule 'prebiotic' can overcome the issues linked with 'probiotic'. Evidently, prebiotic is a class of bioactive molecules grouped together by virtue of their indigestibility inside the gastrointestinal tract by host's own enzyme and possess the ability to selectively stimulate the growth and/or activity of one or limited number of beneficial bacteria in the colon (Gibson and Roberfroid 1995). Among the list of prebiotics, the xylooligosaccharides (XOS) occupy significant niche because they can be produced from cheap, abundantly available and renewable lignocellulosic biomass (Aachary and Prapulla 2011; Carvalho et al. 2013; Jayapal et al. 2013).

The lignocellulosic material represents approximately $50 \%$ of the world biomass with an average annual production of 1 X $10^{10}$ MT worldwide (Sanchez and Cardona 2008). As these are underutilized and often discarded, generation of value added products from those lignocellulosic materials is of immense economic significance. Because of rising demands of corn (Zea mays L.) by various industries, its cultivation is galloping every year throughout the world. Corn husk, the leafy outer covering of corn, contributes approximately $7 \%$ of the plant weight and is available in huge quantity in the form of solid wastes. Presently, these biomaterials are discarded without any further utilization and processing. Nevertheless, compositional analysis of corn husks points out the presence of hemicellulose, which could be translated into high value products such as xylan and XOS (Wang et al. 2008). IUPAC (1980) defines oligosaccharides containing 2-10 xylose units linked by linked by $\square-1-4$ glycosidic bonds are referred as XOS, but molecules with DP > 20 can also be considered as XOS (Moure et al., 2006; Vazquez et al., 2005). However, for food applications xylobiose $(\mathrm{DP}=2)$ is considered to be a XOS (Vazquez et al., 2000).

Corn husk offers a low cost, plentiful and renewable raw material for prebiotic production. With the growing demand for prebiotic, it seems to be the promising raw material for xylan fractionation and XOS production. XOS can be produced by chemical, auto-hydrolysis and enzymatic methods, however, the chemical method involve use of corrosive acids and autohydrolysis needs special equipment for attaining high temperature. The enzymatic method offer safe alternative and obviates special equipments, and is preferred due to simple and safe downstream purification methods.At present, no comprehensive report is available on value addition of corn husks through xylan extraction vis a vis enzymatic production of XOS. Keeping in mind the above perspectives, the present study was aimed to maximize the yield of xylan from corn husks, followed by optimization of variables for enzymatic production of XOS.

\section{MATERIALS AND METHODS}

\section{Raw materials}

Freshly harvested corns were procured from local market of Bengaluru, Karnataka, India and dehusked manually. The husks were dried in forced hot air oven at a temperature of $60 \pm 2^{\circ} \mathrm{C}$ until a constant weight was attained. The dried corn husks were grounded uniformly (particle size $<1 \mathrm{~mm}$ ).

\section{Chemical analysis}

The organic matter content of corn husks was determined after igniting the samples at $550^{\circ} \mathrm{C}$ for $3 \mathrm{~h}$ in Phoneix Microwave furnace. The conventional Micro Kjeldahl method was followed to estimate the crude protein of raw materials. Quantification of cellulose, hemicelluloses and lignin was done according to the fibre fractionation protocol (Van Soest et al. 1991). All the estimations were carried out in duplicate.

\section{Extraction of xylan}

Attempt was made to optimize the concentration of sodium hydroxide $(\mathrm{NaOH})$ and potassium 
hydroxide $(\mathrm{KOH})$ for maximizing the yield of xylan from corn husks. A gradually increasing level (2, 4, 8 and 12\%) of $\mathrm{NaOH}$ and $\mathrm{KOH}$ was applied to $10 \mathrm{gm}$ of ground corn husks with the solid to liquid ratio of 1:10. Alkali treated biomass was subjected to steam application in an autoclave at a temperature of $121^{\circ} \mathrm{C}$ and $15 \mathrm{lbs}$ pressure for $45 \mathrm{~min}$ or incubated at room temperature $\left(25^{\circ} \mathrm{C}\right)$ overnight (16h). The alkali solubilised xylan was collected after filtering through a muslin cloth. The $\mathrm{pH}$ of xylan solution was adjusted to 5.0 by quantitatively adding glacial acetic acid. The xylan of corn husks was precipitated with three volumes of ice cold rectified spirit (commercial grade). The recovered xylan was dried in oven at $60 \pm 2^{\circ} \mathrm{C}$. The xylan was weighed and ground in a grinder-mixer and stored at room temperature untill further analyses. The true and relative yield of xylan was calculated (Samanta et al. 2012). The extraction condition that yielded highest xylan was followed for bulk extraction of xylan.

\section{Analysis of xylan}

The extracted xylan was subjected to the estimation of glucose by GOD/POD kit (Span Diagnostics Ltd, India). The method of Somogyi was followed for the quantification of reducing sugars (Somogyi 1952). The xylan was hydrolyzed with sulphuric acid (Brienzo et al. 2010) and subjected to HPLC analysis (Jayapal et al. 2013). The acid hydrolysate was passed through $0.45 \mu \mathrm{m}$ syringe filter to remove the extraneous materials. The sample was analyzed by HPLC (Agilent, USA), equipped with refractive index detector (RID) using Zorbex carbohydrate analysis column. After setting the column temperature at $25^{\circ} \mathrm{C}, 20 \mu \mathrm{l}$ filtered sample was loaded through manual injector. The sugar monomers were eluted with solvent mixture of acetonitrile and water (63:37) at the flow rate of $0.5 \mathrm{ml} / \mathrm{min}$. The concentration of each sugar was quantified using average peak areas compared to the mixture of standard sugars including xylose, glucose and arabinose and expressed as a percentage.

Fourier transform infrared spectroscopy (FTIR) analysis of the alkali extracted xylan $(5 \mathrm{mg}$, grounded) was done on a Thermo Nicolet FTIR machine, Avatar 370 at $4000-400 \mathrm{~cm}^{-1}$ spectral range with the resolution of $0.9 \mathrm{~cm}^{-1}$ using $\mathrm{KBr}$ beam splitter and DTGS Detector (Ruzene et al. 2008).

\section{Enzymatic production and detection of XOS}

The xylan was subjected to enzymatic hydrolysis using the commercial xylanase (Sigma-Aldrich,
USA). All the enzymatic hydrolysis was carried out in duplicates with $2 \%$ xylan in sodium citrate buffer (Akpinar et al. 2009). In order to optimize the enzymatic process of XOS generation, the input variables were $\mathrm{pH}(4.0,5.0$ and 6.0), temperature $\left(30,40\right.$ and $\left.50^{\circ} \mathrm{C}\right)$, enzyme dose $(2.65,6.625$ and $13.25 \mathrm{U})$ and incubation time (8, 16 and $24 \mathrm{~h})$. The enzyme hydrolysate from all the treatment combinations was collected and analyzed for reducing sugars (Somogyi 1952). The generation of XOS having different degree of polymerization was detected on thin layer chromatographic (TLC) plates (Samanta et al. 2012). The compositional analysis of XOS mixture in the enzyme hydrolysate was carried out in HPLC; as described previously. XOS in the hydrolysate was quantified using average peak areas compared with the mixture of XOS standards $\left(\mathrm{X}_{2}\right.$ and $\left.\mathrm{X}_{3}\right)$. Based on the results of HPLC analysis, optimum treatment $(\mathrm{pH}$, temperature, enzyme dose and incubation time) combination was identified.

\section{Statistical Methods}

The analysis of variance using PROC ANOVA procedure of SAS was performed to test the significance of each independent variable on the yield of reducing sugars. The data obtained from the analysis of reducing sugar content and HPLC analysis of XOS were subjected to the response surface model (RSM) analysis in order to predict the optimum treatment combination.

\section{RESULTS AND DISCUSSION}

\section{Composition of corn husks}

The compositional analysis (expressed as g per 100 $\mathrm{g}$ of dry matter, DM) revealed that the corn husks contained organic matter $97.11 \pm 0.24$, total ash $2.89 \pm 0.18$, crude protein $2.68 \pm 0.11$, neutral detergent fibre $68.87 \pm 0.48$, acid detergent fibre $31.48 \pm 0.36$, cellulose $29.07 \pm 0.16$, hemicellulose $37.39 \pm 0.54$ and acid detergent lignin $2.41 \pm 0.12$. The corn husks were rich in xylan making them a potentially ideal raw material for prebiotic production. The contents of hemicelluloses varied from 33.5 to $44.5 \mathrm{~g}$ per $100 \mathrm{~g}$ corn husks (Kurakake et al. 2001). Because of higher contents of hemicelluloses, corn husks is often recommended as an ideal raw material for the production of several value added products including xylose, xylitol, arabinose and XOS (Yoon et al. 2006). Further, the presence of lower levels of lignin (2.41 $\mathrm{g} / 100 \mathrm{~g} \mathrm{DM}$ ) in the corn husks justified its merit for xylan extraction. 


\section{Extraction of xylan}

Irrespective of the conditions applied in the present investigation, $\mathrm{NaOH}$ was superior to $\mathrm{KOH}$ in solubilising the xylan from the corn husks (Fig.1). The steam application was found to be more efficient than overnight incubation in maximizing the yield of xylan. The relative yield of xylan is presented in Table 1. The actual and relative yields of xylan increased with the increasing concentration of alkali. The relative yield of xylan ranged from 9.1 to $84.6 \%$ and 4.1 to $54.1 \%$ with $\mathrm{NaOH}$ and $\mathrm{KOH}$, respectively. The highest yield was recorded with $12 \%$ alkali $(\mathrm{NaOH}$ and $\mathrm{KOH})$, coupled with steam application. Interestingly, glucose was undetected in the extracted xylan. Further, the extracted xylan contained negligible quantity of reducing sugars $(<0.1 \%)$ as determined by the method of Somogyi (1952).

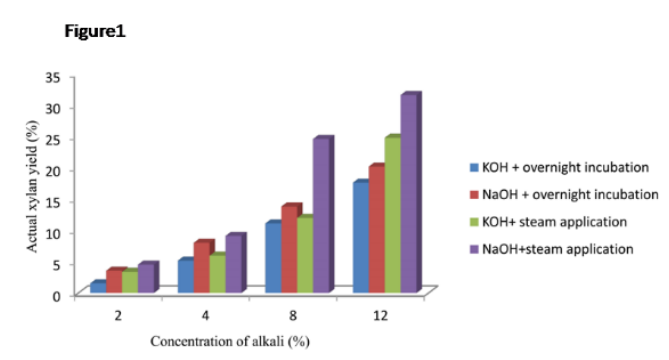

Figure 1 - Effect of alkali and extraction conditions on actual yield of xylan from corn husks

Table 1 - Effect of alkali on the relative yield of xylan from corn husks

\begin{tabular}{|c|c|c|}
\hline \multirow{2}{*}{$\begin{array}{l}\text { Alkali and its } \\
\text { levels }\end{array}$} & \multicolumn{2}{|c|}{ Relative yield of xylan (\%) } \\
\hline & $\begin{array}{l}\text { Steam } \\
\text { application }\end{array}$ & $\begin{array}{l}\text { Overnight } \\
\text { incubation }\end{array}$ \\
\hline \multicolumn{3}{|c|}{ Sodium hydroxide } \\
\hline $2 \%$ & $12.1 \pm 0.24$ & $9.5 \pm 0.68$ \\
\hline $4 \%$ & $24.4 \pm 0.81$ & $21.4 \pm 0.89$ \\
\hline $8 \%$ & $65.8 \pm 2.23$ & $36.9 \pm 2.20$ \\
\hline $12 \%$ & $84.6 \pm 2.19$ & $54.1 \pm 1.95$ \\
\hline \multicolumn{3}{|c|}{ Potassium hydroxide } \\
\hline $2 \%$ & $9.1 \pm 0.16$ & $4.1 \pm 0.22$ \\
\hline $4 \%$ & $15.9 \pm 0.96$ & $13.8 \pm 0.88$ \\
\hline $8 \%$ & $32.1 \pm 1.42$ & $29.7 \pm 2.74$ \\
\hline $12 \%$ & $66.3 \pm 2.98$ & $47.2 \pm 3.64$ \\
\hline
\end{tabular}

The yield of xylan from the plant biomass depends on the linkages and hydrogen bonding with other structural components such as cellulose and lignin and method of extraction. In the present investigation, higher recovery of xylan from corn husks could be attributed to its meagre lignin content (2.4\%). Since, xylan is embedded in the cell walls of the lignocellulosic materials; their isolation in polymeric form is difficult and requires multistep extraction methods to separate from complex structural molecules (Ebringerova et al. 2005). The different procedures of xylan fractionation adopted in the past include physical method and chemical method with different levels of recovery (Carvalho et al. 2013; Samanta et al. 2015). However, application of $12 \% \mathrm{NaOH}$ in combination with steam is reported to ensure almost complete recovery of xylan from natural grass (Samanta et al. 2012), because of effective hydrolysis of ester linkages with alkali in the presence of steam, followed by its solubilisation into the alkali medium (Doner and Hicks 1997; Peng et al. 2010). In the present study, maximizing the xylan yield from corn husks was attempted and a higher recovery (>84\%) of original xylan was realized.

\section{Monomer composition of xylan}

The monomer composition of xylan depends on its source, stage of harvest, method of extraction etc (Saha 2013). Albeit, it is made with diverse group of polysaccharides, but most of the xylans are characterized by the presence of $\beta-(1 \rightarrow 4)$-linked xylose backbone, substituted with short carbohydrate chains (Ebringerova et al. 2005). The HPLC analysis of corn husks xylan reflected xylose $60 \%(1.34 \mathrm{mg} / \mathrm{ml})$, arabinose $25 \%(0.57 \mathrm{mg} / \mathrm{ml})$ and glucose $15 \%(0.32 \mathrm{mg} / \mathrm{ml})$. Evidently, the higher concentration of xylose detected in the acidic hydrolysate of the corn husks xylan further substantiated its importance for selecting the corn husk as starting materials of XOS production.

\section{Fourier transform infrared spectroscopy (FT- IR)}

The alkali extracted xylan of corn husks was subjected to FT-IR analysis (Fig. 2A and 2B). A comparable FT-IR spectrum of xylan was noticed with different levels of $\mathrm{NaOH}$ or $\mathrm{KOH}$. Further, spectral profile of alkali extracted xylan was found to be similar to that of the standard oat spelt xylan. The FT-IR spectra obtained in the present study reflected broad band between 3200 and $3600 \mathrm{~cm}^{-1}$ that might be ascribed to the vibrations of hydroxyl groups in all samples including standard xylan. The spectral profile of alkali extracted xylan of corn husks displayed specific band maxima in the range of $1600-1000 \mathrm{~cm}^{-1}$. However, in case of wheat straw xylan, the FTIR band maxima are found in the wave range of $1200-1000 \mathrm{~cm}^{-1} \mathrm{f}$ (Ruzene et al. 2008). The absorbance bands appeared at 3400, 2900, 1600, 1200, 1100 and $1000 \mathrm{~cm}^{-1}$ wave numbers in the extracted sample were likely to be 
associated with the xylan molecule and reflected the quality of extracted xylan (Samanta et al. 2012). The dearth of notable signal around $1520 \mathrm{~cm}^{-1}$ wave number in the spectral profile indicated the absence of pectin (Kacurakova et al. 1999). The presence of arabinose side chains in the xylan was confirmed from the appearance of low intensity bands nearer to wave numbers of $1166 \mathrm{~cm}^{-1}$ and $986 \mathrm{~cm}^{-1}$. The spectral bands noticed around $1046 \mathrm{~cm}^{-1}$ might be attributed to $\mathrm{C}-\mathrm{O}, \mathrm{C}-\mathrm{C}$ stretching or $\mathrm{C}-\mathrm{OH}$ bending of hemicelluloses molecules.

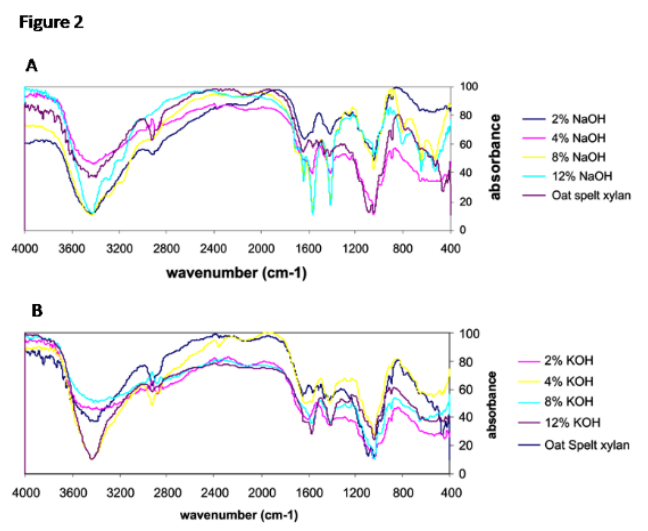

Figure 2 - Fourier Transform Infrared Spectroscopic analysis of xylan obtained from corn husks through different levels of $\mathrm{NaOH}(\mathrm{A})$ and $\mathrm{KOH}(\mathrm{B})$ together with steam application.

\section{Production and detection of xylooligosaccharides}

Out of the several methods of XOS production, enzymatic pathway is often preferred as it neither requires specialized equipment nor invokes extensive downstream processing (Akpinar et al. 2009; Carvalho et al. 2013). Therefore, in the current study, xylanase enzyme was applied to optimize the variables for maximizing the production of XOS. The TLC analysis (Fig. 3A, 3B, $3 \mathrm{C})$ revealed the hydrolysis of corn husks xylan into XOS with different degree of polymerization, namely xylobiose $\left(\mathrm{X}_{2}\right)$ and xylotriose $\left(\mathrm{X}_{3}\right)$ in addition to xylose $\left(\mathrm{X}_{1}\right)$ monomer. The results clearly indicated the greater hydrolysis of xylan into XOS with increasing concentration of enzyme at a particular $\mathrm{pH}$, hydrolysis time and temperature. Similar pattern of enzyme hydrolysis of xylan originated from agricultural wastes has been reported (Akpinar et al. 2009). Conversely, few researchers did not notice higher production of
XOS while increasing the enzyme concentration from 15 to 35U/g of substrate (Yang et al. 2011).

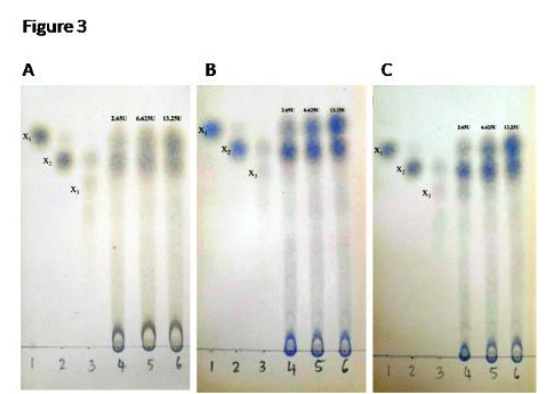

Figure 3 - XOS produced by the enzymatic hydrolysis of corn husk xylan at temperature $30^{\circ} \mathrm{C}, \mathrm{pH} 5.0$ and with incubation time of $8 \mathrm{~h}(\mathrm{~A}), 16 \mathrm{~h}(\mathrm{~B})$ or $24 \mathrm{~h}(\mathrm{C})$. Lane 1: xylose $1 \mu \mathrm{g}$; Lane 2: xylobiose $1 \mu \mathrm{g}$; Lane 3:standard XOS $1 \mu \mathrm{g}$; Lane 4: XOS generated by $2.65 \mathrm{U}$ of xylanase; Lane 5: XOS generated by $6.625 \mathrm{U}$ of xylanase; Lane 6: XOS generated by $13.25 \mathrm{U}$ of xylanase.

However, the same authors reported an enhanced rate of xylan hydrolysis, which is indicative of more xylose than XOS production. In the current study, increasing the duration of hydrolysis from 8 to $16 \mathrm{~h}$ resulted into higher hydrolysis of xylan accompanied by increased XOS production. Although hydrolysis of xylan increased until $24 \mathrm{~h}$ production of XOS was maximum at $16 \mathrm{~h}$ and dide not improve with continued hydrolysis.

The reducing sugar in the enzymatic hydrolysate of xylan is the total carbohydrates present in the form of XOS and xylose. Therefore, reducing sugars concentration was measured in the enzymatic hydrolysate (Table 2). It was noticed that all the variables significantly $(p<0.01)$ influenced the reducing sugars concentration. In the current study, an effective treatment combination to maximize the response (reducing sugar content) could not be deduced through RSM analysis because of the arrival of saddle point. Therefore, post hoc ridge analysis was done to envisage the ideal treatment combinations for maximizing the response. The analysis indicated that an enzyme dose of $10.89 \mathrm{U}$ at $\mathrm{pH}$ of 5.42 and temperature $45.7^{\circ} \mathrm{C}$ for a hydrolysis period of $19.4 \mathrm{~h}$ was optimum to maximize the production of reducing sugars $(5.22 \mathrm{mg} / \mathrm{ml})$. The concentration of reducing sugars in the enzymatic hydrolysate of xylan varies with the source of raw materials (Kiran et al. 2013).

Table 2 - Effect of different variables on reducing sugars concentration (mean \pm SE) in the enzymatic hydrolysate of corn husks xylan 


\begin{tabular}{|c|c|c|c|}
\hline \multicolumn{2}{|c|}{ Variables and their levels } & \multirow{2}{*}{$\begin{array}{l}\text { Reducing sugars }(\mathrm{mg} / \mathrm{ml}) \\
3.91 \pm 0.21\end{array}$} & \multirow{2}{*}{$\begin{array}{l}\text { Ideal conditions for maximizing response } \\
\text { through RSM analysis } \\
5.42\end{array}$} \\
\hline $\mathrm{Ph}$ & 4.0 & & \\
\hline & 5.0 & $3.24 \pm 0.16$ & \\
\hline & 6.0 & $4.09 \pm 0.0 .21$ & \\
\hline$P$ value & & $<0.006$ & \\
\hline \multirow[t]{3}{*}{ Temperature $\left({ }^{\circ} \mathrm{C}\right)$} & 30 & $2.98 \pm 0.19$ & 45.7 \\
\hline & 40 & $3.73 \pm 0.14$ & \\
\hline & 50 & $4.58 \pm 0.21$ & \\
\hline$P$ value & & $<0.001$ & \\
\hline \multirow[t]{3}{*}{ Enzyme dose (U) } & 2.65 & $2.92 \pm 0.15$ & 10.89 \\
\hline & 6.625 & $3.65 \pm 0.17$ & \\
\hline & 13.250 & $4.69 \pm 0.20$ & \\
\hline$P$ value & & $<0.001$ & \\
\hline \multirow[t]{3}{*}{ Incubation time $(\mathrm{h})$} & 8 & $2.59 \pm 0.16$ & 19.4 \\
\hline & 16 & $4.02 \pm 0.15$ & \\
\hline & 24 & $4.68 \pm 0.18$ & \\
\hline $\mathrm{P}$ value & & $<0.001$ & \\
\hline
\end{tabular}

The HPLC analysis revealed hydrolysis of xylan into XOS comprising of mainly $X_{2}$ and $X_{3}$ in addition to $\mathrm{X}_{1}$ (Table 3). Although, no significant influence of $\mathrm{pH}$ and incubation time on the $\mathrm{X}_{2}$ production was noticed, temperature and enzyme dose significantly $(\mathrm{P}<0.01)$ influenced the concentration of $\mathrm{X}_{2}$. On the other hand, all the variables $\mathrm{pH} \quad(\mathrm{P}<0.01)$, temperature $(\mathrm{P}<0.05)$, enzyme dose $(\mathrm{P}<0.01)$, and incubation time $(P<0.01)$ significantly influenced the $X_{3}$ and $X_{1}$ concentration. A gradual increase in the concentration of $\mathrm{X}_{1}$ was observed with the increasing levels of temperature, enzyme dose and incubation time, except $\mathrm{pH}$. In order to find out the best combination of variables to maximise the production of $X_{2}$ and $X_{3}$ keeping the $X_{1}$ production at minimum level, the RSM analysis was performed. The results of the response surface quadratic function analysis indicated the maximum possible yield $\left(9.55 \mathrm{~g} / 100 \mathrm{~g}\right.$ xylan) of $\mathrm{X}_{2}$ could be achieved at $\mathrm{pH} 5.8$ and temperature $44^{\circ} \mathrm{C}$ with $5.73 \mathrm{U}$ of xylanase enzyme incubation for $17.5 \mathrm{~h}$ (Table 4). According to the available reports, the components of XOS vary widely: $\mathrm{X}_{2}(3.42-4.70$ $\mathrm{mg} / \mathrm{ml}), X_{3}(0.34-3.66 \mathrm{mg} / \mathrm{ml}), X_{4}($ nil -1.99 $\mathrm{mg} / \mathrm{ml}$ ) depending upon the source of xylan, xylanase enzyme and hydrolysis factors etc (Yang et al. 2007). Hence, the present investigation was successful in establishing the value addition of corn husks through enzymatic production of prebiotic XOS.

Table 3 - Effect of different variables on the concentration (mean \pm SE) of xylose, xylobiose and xylotriose in the enzymatic hydrolysate of corn husks xylan

\begin{tabular}{|c|c|c|c|c|}
\hline Variables & & $\begin{array}{l}\text { Xylose } \\
(\mathrm{mg} / \mathrm{ml})\end{array}$ & Xylobiose (mg/ml) & Xylotriose $(\mathrm{mg} / \mathrm{ml})$ \\
\hline \multirow[t]{3}{*}{$\mathrm{pH}$} & 4 & $1.883 \pm 0.20$ & $1.368 \pm 0.09$ & $0.786 \pm 0.04$ \\
\hline & 5 & $2.008 \pm 0.22$ & $1.472 \pm 0.07$ & $0.950 \pm 0.04$ \\
\hline & 6 & $1.361 \pm 0.15$ & $1.502 \pm 0.07$ & $0.804 \pm 0.04$ \\
\hline $\mathrm{P}$ value & & 0.045 & 0.444 & 0.006 \\
\hline \multirow[t]{3}{*}{ Temperature $\left({ }^{\circ} \mathrm{C}\right)$} & 30 & $1.241 \pm 0.15$ & $1.270 \pm 0.09$ & $0.760 \pm 0.05$ \\
\hline & 40 & $1.865 \pm 0.19$ & $1.590 \pm 0.07$ & $0.886 \pm 0.03$ \\
\hline & 50 & $2.150 \pm 0.21$ & $1.482 \pm 0.07$ & $0.891 \pm 0.03$ \\
\hline$P$ value & & 0.003 & 0.010 & 0.030 \\
\hline
\end{tabular}




$\begin{array}{lllll}\text { Enzyme dose (U) } & 2.650 & 1.007 \pm 0.08 & 1.575 \pm 0.07 & 0.896 \pm 0.04 \\ & 6.625 & 1.619 \pm 0.15 & 1.567 \pm 0.08 & 0.880 \pm 0.04 \\ & 13.250 & 2.611 \pm 0.19 & 1.204 \pm 0.07 & 0.761 \pm 0.03 \\ \text { P value } & & <0.001 & <0.001 & 0.031 \\ \text { Incubation time (h) } & 8 & 1.199 \pm 0.14 & 1.324 \pm 0.09 & 0.744 \pm 0.04 \\ & 16 & 1.882 \pm 0.19 & 1.543 \pm 0.06 & 0.900 \pm 0.04 \\ & 24 & 2.178 \pm 0.21 & 1.475 \pm 0.07 & 0.893 \pm 0.03 \\ \text { P value } & & 0.001 & 0.121 & 0.006\end{array}$

Table 4 - Response Surface quadratic function analysis to determine the optimum combination of variables for maximising XOS production

\begin{tabular}{llllllll}
\hline $\begin{array}{l}\text { Components } \\
\text { of XOS }\end{array}$ & Approach & $\mathrm{pH}$ & $\begin{array}{l}\text { Temperature } \\
\left({ }^{\circ} \mathrm{C}\right)\end{array}$ & $\begin{array}{l}\text { Enzyme } \\
\text { dose }(\mathrm{U})\end{array}$ & $\begin{array}{l}\text { Incubation } \\
\text { time }(\mathrm{h})\end{array}$ & $\mathrm{RS}$ & Ridge \\
\hline Xylose & Minimize & 5.59 & 34.59 & 5.24 & 13.59 & -3.73 & 1.2564 \\
Xylobiose & Maximize & 5.79 & 44.02 & 5.73 & 17.49 & 1.83 & 1.91 \\
Xylotriose & Maximize & 5.08 & 41.27 & 4.43 & 18.96 & 1.11 & - \\
\hline
\end{tabular}

\section{CONCLUSION}

In conclusion, effective hydrolysis of corn husks derived xylan into XOS with different degree of polymerisation could be established. The RSM analysis indicated higher production of $\mathrm{X}_{2}$ (1.91 $\mathrm{mg} / \mathrm{ml}$ ) is possible through the hydrolysis of xylan at $\mathrm{pH} 5.8$, temperature $44^{\circ} \mathrm{C}$, incubation time $17.5 \mathrm{~h}$ and $5.73 \mathrm{U}$ of xylanase. These findings underline the value of corn husks as an ideal raw material for xylan production vis a vis its translation into prebiotic XOS.

\section{REFERENCES}

Aachary AA, Prapulla S G. Xylooligosaccharides (XOS) as an emerging prebiotic: microbial synthesis, utilization, structural characterization, bioactive properties and applications. Compr. Rev. Food Sci. Food Saf. 2011; 10: 2-16.

Akpinar O, Erdogan K, Bostanci S. Enzymatic production of xylooligosaccharides from selected agricultural wastes. Food Bioprod. Process. 2009; 87: 145-151.

Brienzo M, Carvalho W, Milagres AMF. Xylooligosaccharides production from alkali pretreated sugarcane bagasse using xylanase from
Thermoascus aurantiacus. Appl. Biochem. Biotechnol. 2010; 162: 1195-1205.

Carvalho AFA, Neto PO, Silva DF, Pastore GM. Xylooligosaccharides from lignocellulosic materials: chemical structure, health benefits and production by chemical and enzymatic hydrolysis. Food Res. Int. 2013; 51: 75-85.

Doner LW, Hicks KB. Isolation of hemicelluloses from corn fiber by alkaline hydrogen peroxide extraction. Cereal Chem. 1997; 74: 176-181.

Ebringerova A, Hromadkova Z, Heinze T. Hemicellulose. Adv. Polym. Sci. 2005; 186: 1-67.

Gibson GR, Roberfroid MB. Dietary modulation of the human colonic microbiota: introducing the concept of prebiotics. J. Nutr. 1995 125: 1401-1412.

IUPAC - Abbreviated Terminology of Oligosaccharide Chains - Recommendations -IUB-IUPAC. Joint Commission on Biochemical Nomenclature (Jcbn). J. Biol. Chem. 1980; 257:3347-3351.

Jayapal N, Samanta AK, Kolte AP, Senani S, Sridhar M, Suresh KP, Sampath KT. Value addition to sugarcane bagasse: xylan extraction and its process optimization for xylooligosaccharides production. Ind. Crop. Prod. 2013; 42: 14-24.

Kacurakova M, Wellner N, Ebringerova A, Hromadkova Z, Wilson RH, Belton PS. Characterization of xylantype polysaccharides and associated cell wall components by FTIR and FT-Raman Spectroscopy. Food Hydrocolloid. 1999;13: 35-41.

Kiran EU, Akpinar O, Bakir U. Improvement of enzymatic xylooligosaccharides production by the 
co-utilization of xylans from different origins. Food Bioprod. Process. 2013;91: 565 -574.

Kurakake M, Kisaka W, Ouchi K, Komaki T. Pretreatment with ammonia water for enzymatic hydrolysis of corn husk, bagasse, and switch grass. Appl. Biochem. Biotechnol. 2001; 90: 251- 259.

Moure A, Gullon P, Dominguez H, Parajo JC. Advances in the manufacture, purification and applications of xylo-oligosaccharides as food additives and nutraceuticals. Process Biochem. 2006; 41:19131923.

Peng F, Ren JL, Xu F, Bian J, Peng P, Sun RC. Fractional studies of alkali soluble hemicelluloses obtained by graded ethanol precipitation from sugar cane bagasse. J. Agric. Food Chem. 2010; 58: 17681776.

Reid G. Probiotics and prebiotics: Progress and challenges. Int. Dairy J. 2008; 18: 969-975.

Ruzene DS, Silva PD, Vicente AA, Goncalves AR, Teixeira JA. An alternative application to the Portuguese agro industrial residue: wheat straw. Appl. Biochem. Biotechnol. 2008; 147: 85-96.

Saha BC. Hemicellulose bioconversion. J. Ind. Microbiol. Biotechnol. 2003; 30: 279-291.

Samanta AK, Jayapal N, Kolte AP, Senani S, Sridhar M, Suresh KP, Sampath KT. Enzymatic production of xylooligosaccharides from alkali solubilized xylan of natural grass (Sehima nervosum). Bioresour. Technol. 2012; 112: 199-205.

Samanta AK, Jayapal N, Jayaram C, Roy S, Kolte AP, Senani S, Sridhar M. Xylooligosaccharides as prebiotics from agricultural by-products: Production and applications. Bioact. Crabohydr. Dietary Fibre. 2015; 5: 62-71.

Sanchez OJ, Cardona CA. Trends in biological production of fuel ethanol from different feedstocks. Bioresour. Technol. 2008; 99: 52705295.

Somogyi M. Notes on sugar determination. J. Biol. Chem. 1952; 195: 19-23.

Van Soest PJ, Robertson JB, Lewis BA. Methods for dietary fiber, neutral detergent fiber, and non-starch polysaccharides in relation to animal nutrition. $J$. Dairy Sci. 1991; 74: 3583-3597.

Vazquez MJ, Alonso JL, Dominguez H, Parajo JC. Xylooligosaccharides: manufacture and applications. Trends Food Sci. Technol. 2000; 11:387-393.

Vazquez MJ, Garrote G, Alonso JL, Dominguez H, Parajo JC. Refining of autohydrolysis liquors for manufacturing xylooligosaccharides: evaluation of operational strategies. Bioresour. Technol. 2005; 96:889-896.

Wang B, Cheng B, Feng H. Enriched arabinoxylan in corn fiber for value added products. Biotechnol. Lett. 2008; 30: 275-279.

Yang CH, Yang SF, Liu WH. Production of xylooligosaccharides from xylan by extracellular xylanase from Thermobifida fusca. J.Agric. Food Chem. 2007; 55: 3955-3959.

Yang H, Wang K, Song X, Feng X. Production of xylooligosaccharides by xylanase from Pichiastipitis based on xylan preparation from triplod Popilas tomentosa. Bioresour. Technol. 2011; 102: 71717176.

Yoon KY, Woodams EE, Hang YD. Enzymatic production of pentoses from the hemicelluloses fraction of corn residues. LWT Food Sci. Technol. 2006; 39: 387-391. 